\title{
One-Year Follow-Up after Endobronchial Valve Treatment in Patients with Emphysema without Collateral Ventilation Treated in the STELVIO Trial
}

\author{
Karin Klooster Jorine E. Hartman Nick H.T. ten Hacken Dirk-Jan Slebos \\ University of Groningen, and Department of Pulmonary Diseases, University Medical Center Groningen, \\ Groningen, The Netherlands
}

\section{Keywords \\ Chronic obstructive pulmonary disease - Emphysema . Bronchoscopy - Bronchoscopic lung volume reduction . One-way valve $\cdot$ Collateral ventilation}

\begin{abstract}
Background: One-way endobronchial valve (EBV) treatment has shown safety and efficacy at 6 months after treatment in patients with severe emphysema and confirmed absence of interlobar collateral ventilation. Longer followup in this subgroup is not available. Objectives: To investigate the efficacy and safety of EBV treatment of the STELVIO cohort at a 1-year follow-up. Methods: Emphysema patients who have been treated with EBV in the STELVIO trial were invited for a voluntary 1-year follow-up visit. Both the original treatment group and the control group who crossed over to treatment have been included. Analyses are performed on the patients who attended the 1-year follow-up visit. Results: Sixty-four patients received EBV treatment. At 1 year, 40 patients ( 26 female; mean age $59 \pm 8$ years; $\mathrm{FEV}_{1}$ $0.86 \pm 0.29 \mathrm{~L} ; \mathrm{RV} 4.56 \pm 1.00 \mathrm{~L} ; 6 \mathrm{MWD} 367 \pm 78 \mathrm{~m}$; and SGRQ $56 \pm 13$ points) visited the hospital. Significant improvements $(p<0.001)$ were found for $\mathrm{FEV}_{1}(+17 \%, 95 \% \mathrm{Cl}, 11$ to 24), RV (-687 mL, 95\% Cl, -918 to -456$)$, 6MWD (+61 m, 95\%
\end{abstract}

\begin{tabular}{ll}
\hline KARGER & $\begin{array}{l}\text { ( } 2016 \text { The Author(s) } \\
\text { Published by S. Karger AG, Basel }\end{array}$ \\
E-Mail karger@karger.com & $\begin{array}{l}\text { Karger } \\
\text { www.karger.com/res }\end{array}$ \\
& $\begin{array}{l}\text { This article is licensed under the Creative Commons Attribution- } \\
\text { NonCommercial-NoDerivatives 4.0 International License (CC BY- } \\
\text { NC-ND) (http://www.karger.com/Services/OpenAccessLicense). } \\
\text { Usage and distribution for commercial purposes as well as any dis- } \\
\text { tribution of modified material requires written permission. }\end{array}$
\end{tabular}

$\mathrm{Cl}, 42$ to 80 ), and SGRQ (-11 points, $95 \% \mathrm{Cl},-17$ to -6$)$. Two patients died: 1 after 58 days due to progressive respiratory failure and 1 after 338 days of follow-up due to a myocardial infarction. Seventeen percent of the patients underwent valve replacement and $22 \%$ of the initially treated patients had permanent valve removal. In $22 \%$ of the patients, pneumothoraces occurred before 6 months, and none occurred between 6 and 12 months. Conclusions: EBV treatment results in clinically relevant benefits at 1 year of follow-up. Maintenance bronchoscopies to achieve this are needed. This study supports the use of EBV treatment in carefully selected patients with severe emphysema without collateral ventilation.

(C) 2016 The Author(s)

Published by S. Karger AG, Basel

\section{Introduction}

Recently published studies [1-3] have shown that oneway endobronchial valve (EBV) treatment results in clinically and statistically significant effective improvements in lung function, exercise tolerance, and quality of life. These studies have highlighted the importance of careful patient selection, particularly using the Chartis system to 
demonstrate absence of interlobar collateral ventilation, as a basis for the success of this treatment.

However, treatment success is also accompanied with some risk, particularly an approximately $20 \%$ incidence of the treated patients developing pneumothorax in the early postbronchoscopy phase. Another, less frequent complication was the loss of lung volume reduction due to granulation tissue formation around the valves and subsequent valve dislocation, raising the question of whether the risks for these complications continue to be present beyond 6 months of follow-up. The risk for pneumonia and exacerbations after obstructing the airways with a foreign body like the EBV is expected to be high, but the 6-month data of the STELVIO trial were reassuring in that perspective. Finally, one could anticipate that, since emphysema is a progressive disease, disease progression in the nontreated ipsilateral lobe may negatively influence the effects of successful lung volume reduction over the course of time. Successful lung volume reduction of the target lobe increases mechanical stress and overexpansion of the nontreated lobe and induces compensatory emphysema, associating with loss of the original lung volume reduction effect [4]. In other words: does lung volume reduction persist after 6 months of treatment?

The aims of this uncontrolled study are to investigate the efficacy and safety of EBV treatment of the open-label STELVIO cohort at a 1-year follow-up. This follow-up study lacks a control group because the control group patients in the STELVIO trial were also crossed over and treated with EBV after their 6-month follow-up, as per the original study protocol.

\section{Methods}

\section{Patients}

We included patients who were previously treated with oneway EBV in the "STELVIO trial" (trial registration: NTR2876) [1] and had severe emphysema, hyperinflation, marked dyspnea irrespective of heterogeneous or homogeneous distribution, and a confirmed absence of interlobar collateral ventilation measured with the Chartis system. The study was approved by the University Medical Center Groningen Medical Ethics Committee, and all participants signed informed consent.

\section{Chartis Assessment and EBV Treatment}

The procedure has been described before [1]. Briefly, collateral ventilation was assessed under conscious sedation using the Chartis system (Pulmonx, Redwood City, CA, USA). The EBV (Zephyr ${ }^{\circledR}$; Pulmonx) were placed in all (sub)segments of the target lobe under general anesthesia or conscious sedation [1].

In the initial study, the "STELVIO trial," EBV treatment was performed in 64 patients, of whom 34 were randomized to the EBV group, and 30 patients were treated as "crossover" patients after initially having been randomized to the control group. All treated patients had proven absence of collateral ventilation confirmed with the Chartis assessment [1].

\section{Study Design}

Patients were previously randomized $1: 1$ to the EBV group or to the control group. Patients randomized to the EBV group received the treatment immediately and underwent a 6-month follow-up visit. Patients in the control group continued to receive standard medical care, underwent a 6-month follow-up visit, and afterwards received the EBV treatment. This crossover control group underwent a 6-month posttreatment follow-up visit. All patients exited the study following completion of the 6-month posttreatment evaluations. Subsequently, all patients, except patients whose valves had to be removed after treatment, were invited for a voluntary evaluation visit 1 year after valve treatment.

\section{Measurements}

At the 1-year follow-up, we performed pulmonary function measurements, a 6-min walk test, and chest X-ray in the patients, and the patients completed questionnaires. Patients were also evaluated by a physician who reported on the patients' health status during the past year. Pulmonary function tests (Jaeger MasterScreen $^{\mathrm{TM}}$; CareFusion, Germany) were performed according to ATS/ERS guidelines $[5,6]$. The 6-min walk test was performed as per ATS recommendations [7]. Health-related quality of life was measured by the St. George's Respiratory Questionnaire (SGRQ) $[8,9]$, and dyspnea severity was measured by the modified Medical Research Council (mMRC) dyspnea scale [10]. The BODE score was calculated at baseline as well as after 6 months and 1 year of follow-up [11]. If patients did not visit our hospital for their followup, available spirometry data from other hospitals were collected. This was also necessary for patients whose valves had to be removed after treatment and for patients who were initially not treated with EBV due to either positive collateral ventilation or local airway anatomy not compliant with valve treatment. The baseline inspiratory high-resolution CT scan was used to assess emphysema distribution for the treated lung. Less than 15\% difference in destruction score between treatment lobe and nontreatment ipsilateral lobe in the EBV target lung was defined as "homogeneous" and more than $15 \%$ as "heterogeneous" [1].

\section{Safety Data}

Survival was evaluated up to 1 year in all patients who underwent screening assessment in the initial STELVIO study. Serious adverse event data were collected during the study from all patients who were treated with EBV.

\section{Outcome Measures}

Efficacy outcome measures were improvement in change from baseline to the 1-year follow-up in pulmonary function (spirometry and body plethysmography), 6-min walk distance (6MWD), and the SGRQ total score. Clinical response was defined using established minimal clinically important differences (MCID) for $\mathrm{FEV}_{1}: 10 \%$ [12], residual volume (RV): $-430 \mathrm{~mL}$ [13], 6MWD: $26 \mathrm{~m}$ [14], and SGRQ: -4 points [15] and -7 points [16].

\section{Statistical Analysis}

Statistical comparisons for the change from baseline to 6 or 12 months of follow-up were performed using paired $t$ tests or, in case 


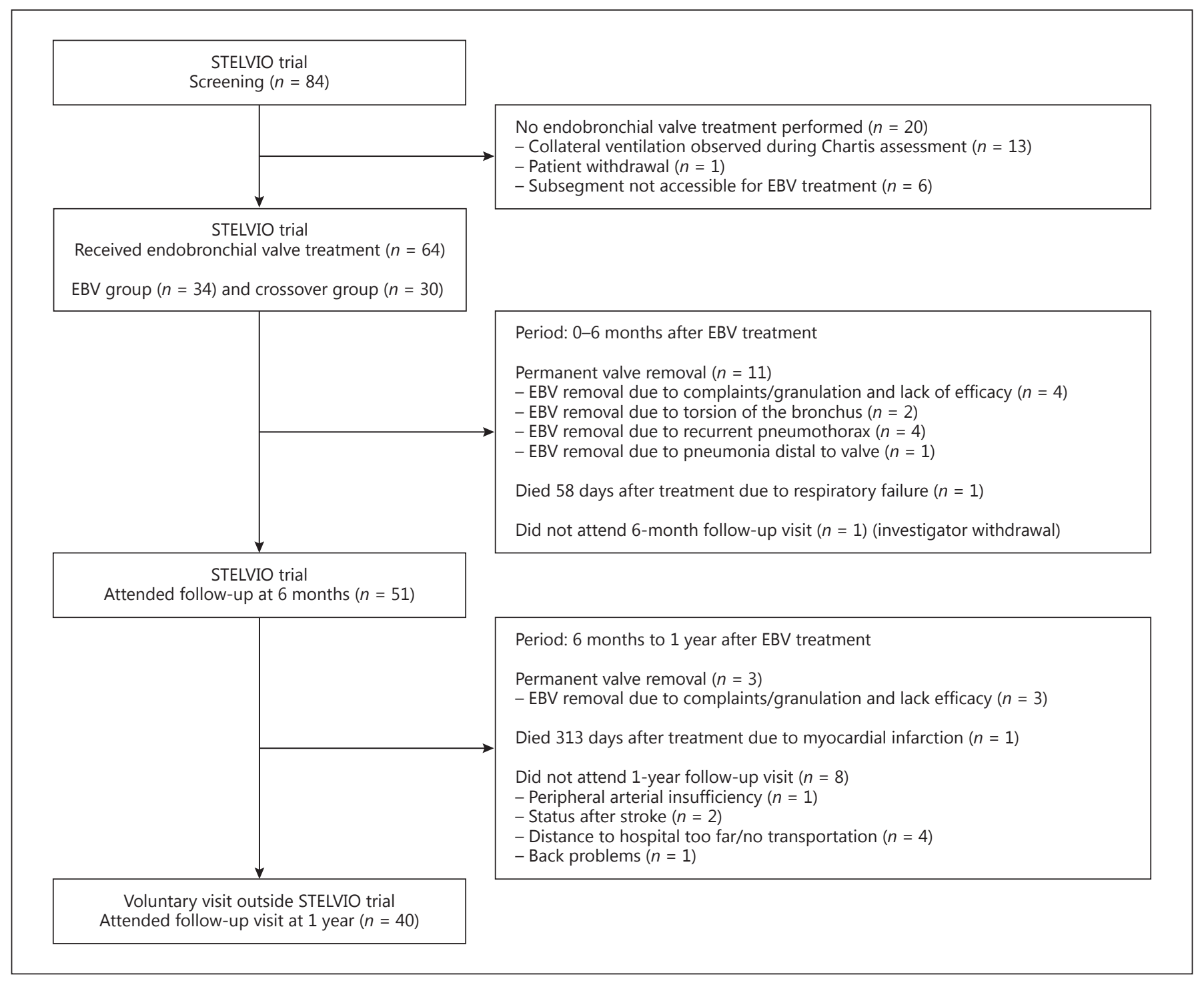

Fig. 1. Study flowchart. EBV, endobronchial valve.

of non-normally distributed data, the Wilcoxon signed-rank test was used to compare the outcomes in change from baseline to 6 or 12 months of follow-up. To adjust for multiple testing, $p$ values of $<0.025$ were considered to indicate statistical significance. SPSS Statistics version 22 (IBM, Armonk, NY, USA) was used for all analyses.

\section{Results}

\section{Study Patients}

The initial STELVIO study was performed between June 2011 and November 2014, with the last patient reaching the 1-year follow-up in October 2015 [1]. Eighty- four patients were screened for eligibility. Of these, 13 patients were excluded for proven presence of interlobar collateral ventilation, 6 were excluded because of local airway anatomy not accessible for EBV placement, and 1 patient was withdrawn, resulting in 64 patients who were treated with EBV [1]. Of the 64 treated patients, $2(3 \%)$ patients died and $14(22 \%)$ patients were not able to retain the EBV throughout the 1-year study period, which was related to valve removal procedures: $4 \mathrm{sec}-$ ondary to a pneumothorax, 2 due to airway torsion, 7 due to granulation tissue formation, lack of efficacy, and complaints, and 1 due to pneumonia distal to valve. Eight patients did not attend the 1-year follow-up visit for 
Table 1. Patient characteristics at baseline $(n=40)$

\begin{tabular}{|c|c|c|c|}
\hline Characteristics & $\begin{array}{l}\text { All patients } \\
(n=40)\end{array}$ & $\begin{array}{l}\text { Homogeneous } \\
\text { distribution }(n=21)\end{array}$ & $\begin{array}{l}\text { Heterogeneous } \\
\text { distribution }(n=19)\end{array}$ \\
\hline Age, years & $59 \pm 8$ & $59 \pm 7$ & $59 \pm 9$ \\
\hline Female/male & $26 / 14$ & $12 / 9$ & $14 / 5$ \\
\hline Pack-years & $36 \pm 21$ & $32 \pm 18$ & $40 \pm 24$ \\
\hline Body mass index & $24.6 \pm 4.1$ & $24.7 \pm 4.0$ & $24.5 \pm 4.3$ \\
\hline BODE index, points & $4.9 \pm 1.3$ & $5.0 \pm 1.5$ & $4.9 \pm 1.3$ \\
\hline $\mathrm{FEV}_{1}, \mathrm{~L}$ & $0.86 \pm 0.29$ & $0.85 \pm 0.31$ & $0.88 \pm 0.27$ \\
\hline $\mathrm{FEV}_{1}, \%$ predicted & $30 \pm 8$ & $30 \pm 9$ & $32 \pm 7$ \\
\hline FVC, L & $2.68 \pm 0.90$ & $2.76 \pm 0.94$ & $2.59 \pm 0.88$ \\
\hline FVC, \% predicted & $77 \pm 17$ & $77 \pm 19$ & $77 \pm 16$ \\
\hline $\mathrm{FEV}_{1} / \mathrm{FVC}, \%$ & $33 \pm 8$ & $32 \pm 7$ & $35 \pm 8$ \\
\hline TLC, L & $7.59 \pm 1.39$ & $7.66 \pm 1.34$ & $7.50 \pm 1.46$ \\
\hline TLC, \% predicted & $130 \pm 11$ & $129 \pm 12$ & $131 \pm 10$ \\
\hline $\mathrm{RV}, \mathrm{L}$ & $4.56 \pm 1.00$ & $4.57 \pm 0.98$ & $4.55 \pm 1.05$ \\
\hline RV, \% predicted & $217 \pm 35$ & $214 \pm 38$ & $219 \pm 33$ \\
\hline RV/TLC, \% & $60 \pm 8$ & $60 \pm 9$ & $61 \pm 8$ \\
\hline IC/TLC, \% & $25 \pm 6$ & $25 \pm 7$ & $24 \pm 6$ \\
\hline DLCO, $\%$ predicted & $40 \pm 10$ & $41 \pm 10$ & $40 \pm 10$ \\
\hline $\mathrm{PaCO}_{2}, \mathrm{kPa}$ & $5.12 \pm 0.79$ & $5.21 \pm 0.89$ & $5.03 \pm 0.69$ \\
\hline $\mathrm{PaO}_{2}, \mathrm{kPa}$ & $9.00 \pm 1.18$ & $8.91 \pm 1.32$ & $9.10 \pm 1.06$ \\
\hline 6MWD, m & $367 \pm 79$ & $358 \pm 77$ & $377 \pm 81$ \\
\hline mMRC dyspnea score & $2.6 \pm 0.7$ & $2.5 \pm 0.8$ & $2.6 \pm 0.7$ \\
\hline SGRQ total score & $56.2 \pm 12.8$ & $55.6 \pm 11.7$ & $56.9 \pm 14.0$ \\
\hline Target lobe voxels -950 HU, \% & $47 \pm 7$ & $45 \pm 5$ & $49 \pm 8$ \\
\hline Target lobe volume, $\mathrm{mL}$ & $1,888 \pm 635$ & $1,842 \pm 644$ & $1,938 \pm 639$ \\
\hline
\end{tabular}

Patient characteristics $(n=40)$ at baseline are presented as numbers or as mean \pm standard deviation. There were no significant differences between the homogeneous and heterogeneous group, except for target lobe voxels (\%) $(p=0.038)$. Baseline characteristics were similar between the patients who attended the 1-year follow-up $(n=40)$ and those who did not attend the 1-year follow-up. $\mathrm{FEV}_{1}$, forced expiratory volume in $1 \mathrm{~s}$; FVC, forced vital capacity; TLC, total lung capacity; RV, residual volume; IC, inspiratory capacity; DLCO, carbon monoxide diffusion capacity; $\mathrm{PaCO}_{2}$, arterial carbon dioxide pressure; $\mathrm{PaO}_{2}$, arterial oxygen pressure; SGRQ, St. George's Respiratory Questionnaire; mMRC, modified Medical Research Council; BODE index, combined score of body mass index, airflow obstruction, dyspnea, and exercise capacity.

various reasons (Fig. 1; online suppl. Table 1, see www. karger.com/doi/10.1159/000453529). At 1 year, 48 (78\%) patients retained their valves, of whom $40(83 \%)$ visited the hospital for follow-up assessments. The baseline characteristics of these 40 patients are shown in Table 1, and the study flowchart is presented in Figure 1. Baseline characteristics were similar between the patients who attended the 1-year follow-up $(n=40)$ compared to the patients who did not attend the 1-year follow-up.

\section{Efficacy Outcomes}

Among patients who attended the 1-year follow-up visit, significant improvements (all $p<0.001$ ) between baseline and 1-year follow-up were measured: $\mathrm{FEV}_{1}$ $+17 \%$ (95\% CI, 11 to 24$)$, RV $-687 \mathrm{~mL}$ (95\% CI, -918 to
$-456), 6 \mathrm{MWD}+61 \mathrm{~m}(95 \% \mathrm{CI}, 42$ to 80$)$, and SGRQ total score -11 points ( $95 \% \mathrm{CI},-17$ to -6 ). All these results exceeded the established MCID. At the 1-year follow-up, improvements in FVC and 6MWD were comparable to those observed at the 6-month evaluation. The 1-year results for $\mathrm{FEV}_{1}, \mathrm{RV}$, and SGRQ were slightly declined compared to those at the 6-month evaluation but still clinically meaningful (exceeded the MCID) and significantly improved compared to baseline. At 1 year, no significant differences, except for $\mathrm{FEV}_{1}$, were found between heterogeneous and homogeneous patients as well as between patients who were treated in the upper lobes and those treated in the lower lobes (Table 2; Fig. 2). Figure 3 shows the individual patient outcomes compared to baseline at 6 months and 1 year of follow-up of the 


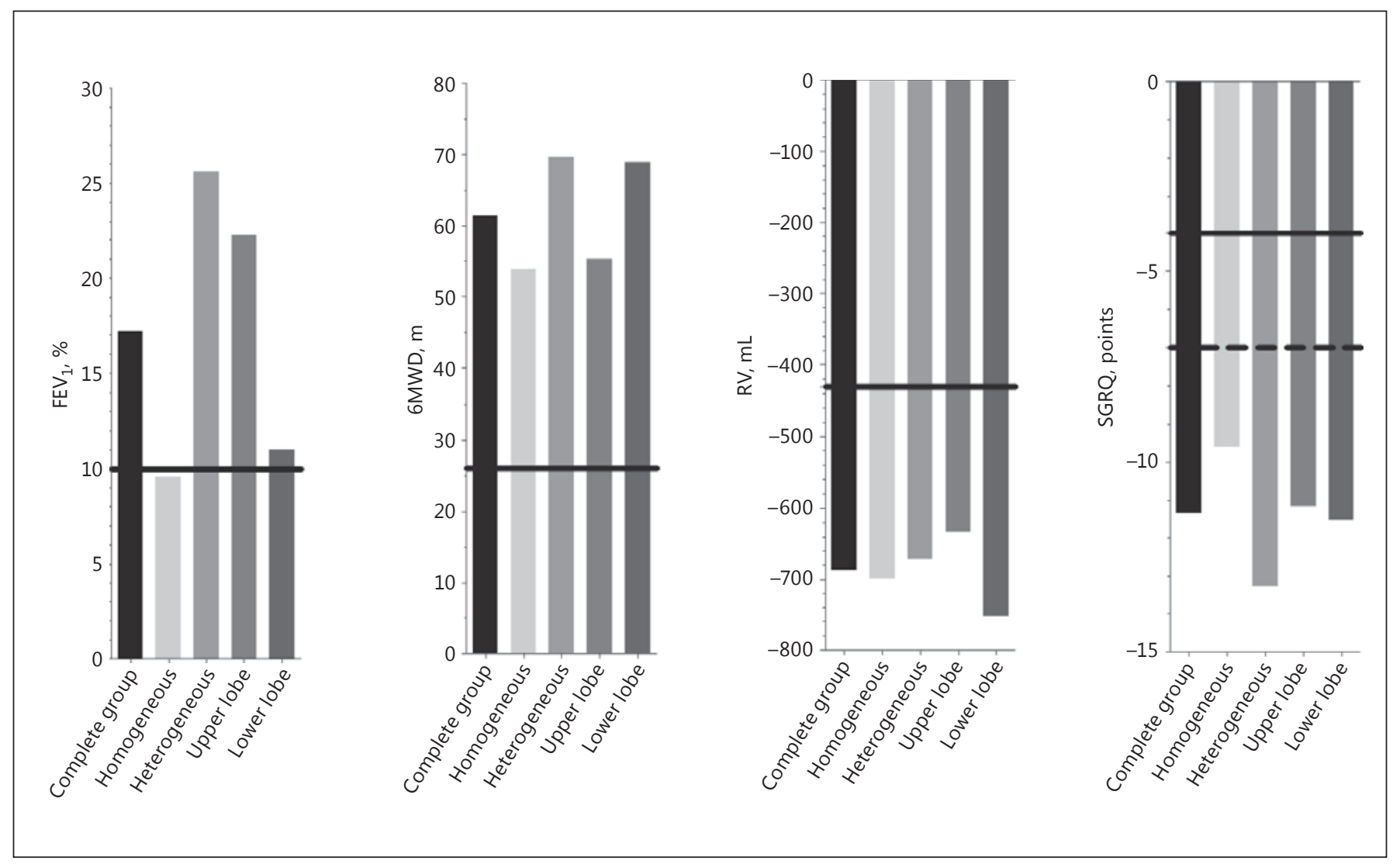

Fig. 2. Efficacy outcomes compared to baseline at the 1-year follow-up of the patients who attended the 1-year follow-up visit $(n=40)$. The data are presented as mean change from baseline to 1 year of follow-up for 5 different groups: complete group $(n=40)$, homogeneous distribution $(n=21)$, heterogeneous distribution
( $n=19)$, upper lobe treatment $(n=22)$, and lower lobe treatment $(n=18)$. Horizontal bars represent the MCID value for each outcome. $\mathrm{FEV}_{1}$, forced expiratory volume in $1 \mathrm{~s} ; 6 \mathrm{MWD}$, 6-min walk distance; RV, residual volume; SGRQ, St. George's Respiratory Questionnaire. patients who attended the voluntary 1-year follow-up visit $(n=40)$.

The BODE index at 1 year showed an improvement from baseline of -1.13 points ( $95 \% \mathrm{CI},-1.5$ to -0.7 ; $p<$ $0.001)$. Eight patients who retained the valves did not attend the 1-year follow-up visit: 4 patients did not have transportation, 2 patients were not able to attend the visit due to a previous stroke, 1 patient due to peripheral artery insufficiency, and 1 due to back problems. Spirometry data were retrieved for 7 of these patients. Median (minimum-maximum) changes in key outcome measures from baseline to 6 months and a median of 528 days (267-770), respectively, after treatment were: $\mathrm{FEV}_{1}$ $+13.1 \%(-7.8$ to +58.9$)$ and $+6.3 \%(-28.0$ to +55.6$)(p=$ $0.176)$, and $\mathrm{FVC}+17.8 \%(-0.5$ to +37$)$ and $+11.9 \%(-15.4$ to +23.5$)(p=0.091)$. The individual data are shown in the online supplementary Table 1.
Fourteen patients were not able to retain the EBV up to 1 year. Spirometry data were retrieved for 7 of these patients. At a median of 399 days (minimum 62 days, maximum 826 days) after valve removal, the mean change from baseline in $\mathrm{FEV}_{1}$ was $+2.8 \%$ (95\% CI, -15 to $21 ; p=0.743)$ and in $\mathrm{FVC}+4.9 \%(95 \% \mathrm{CI},-12$ to $22 ; p=$ 0.539 ).

Twenty patients of the initial 84 patients screened were not treated with EBV. At a median of 400 days (minimum 106 days, maximum 834 days) after screening, the mean change from baseline for $\mathrm{FEV}_{1}$ was $-3.5 \%$ (95\% CI, -12 to $5 ; p=0.415)$ and for FVC $-1.1 \%(95 \% \mathrm{CI},-12$ to 10 ; $p=0.830)$.

\section{Serious Adverse Events}

Of the 64 treated patients, 2 (3\%) deaths occurred at the 1-year follow-up (Table 3). One death was due to pro- 
Table 2. Mean changes from baseline to 6 months and 1 year of follow-up in the patients who attended the voluntary visit at 1 year $(n=40)$

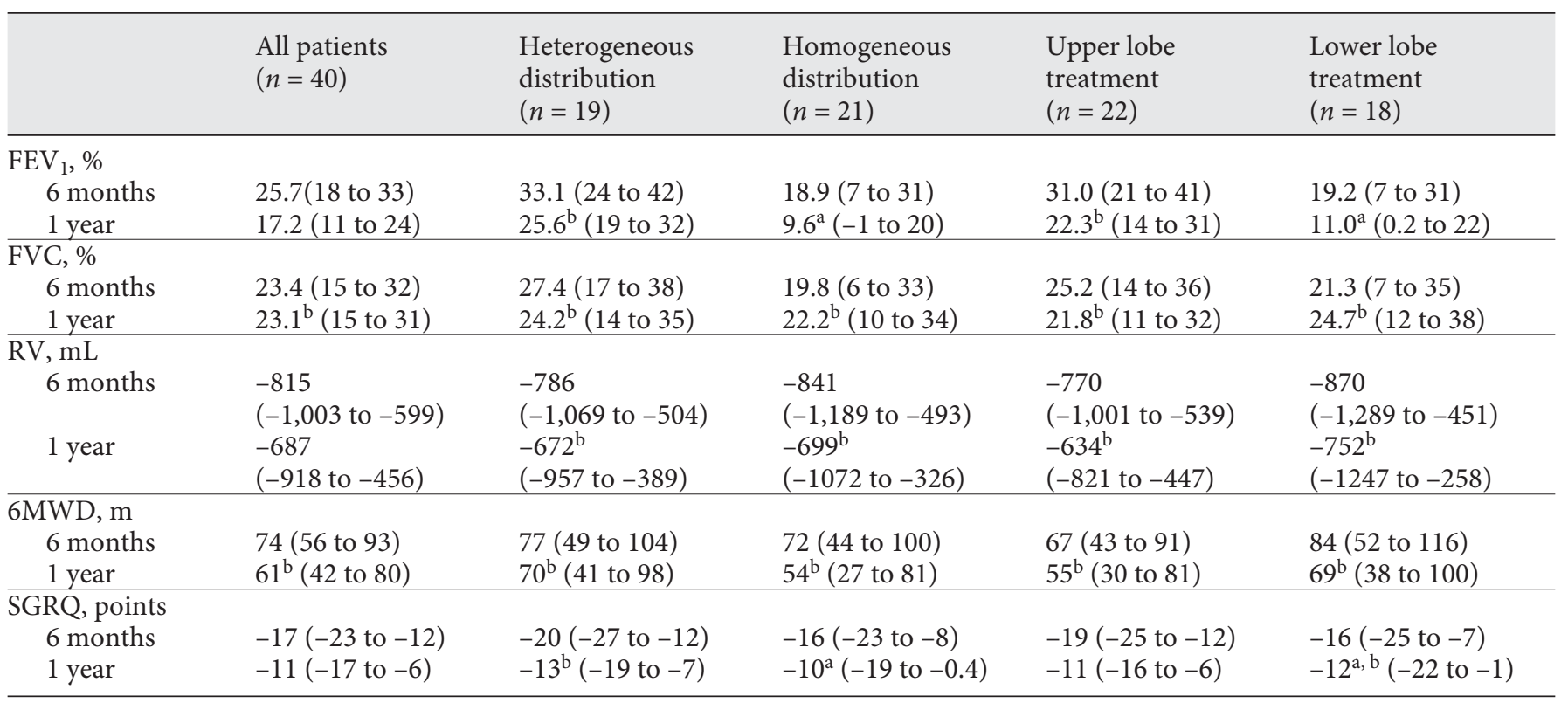

Of the 21 patients with homogeneous distribution, 15 patients received treatment in the lower lobe, and of the 19 patients with heterogeneous distribution, 3 patients received treatment in the lower lobe. The paired $t$ test was used to calculate mean differences ( $95 \%$ confidence intervals) in changes from baseline to 6 months and 1 year and from 6 months to 1 year. To adjust for multiple testing, $p$ values $<0.025$ were considered to indicate statistical significance. $\mathrm{FEV}_{1}$, forced expiratory volume in $1 \mathrm{~s}$; FVC, forced vital capacity; RV, residual volume; 6MWD, distance on 6 min walk test; SGRQ, St. George's Respiratory Questionnaire.

${ }^{\mathrm{a}}$ Change from baseline was not significant $(p>0.025) .{ }^{\mathrm{b}}$ Change from 6 to 12 months of follow-up was not significant $(p>0.025)$.

gressive respiratory failure (58 days after treatment), and one was due to a myocardial infarction (313 days after treatment). At the 1-year follow-up, 9 chronic obstructive pulmonary disease exacerbations and 5 pneumonias requiring hospitalization were reported. Serious treatmentrelated adverse events included pneumothorax $(22 \%$ of all treated patients) [1] and events requiring valve replacement $(17 \%$ of all treated patients) or permanent valve removal ( $22 \%$ of all treated patients). Pneumothoraces occurred only in the first 6 months: 12 within 2 days of EBV treatment, 1 at 19 days after treatment, and 1 at 126 days after treatment. In the patients $(n=20)$ who did not receive EBV treatment, 2 (10\%) deaths were recorded at 160 and 267 days after the screening visit, both due to chronic obstructive pulmonary disease progression.

\section{Discussion}

One-way EBV treatment provides significant clinical benefits for carefully selected patients with severe emphysema, a patient group with limited treatment options.
One year after EBV treatment, there were significant improvements in pulmonary function, exercise capacity, and quality of life compared to baseline values. This improvement exceeded the established MCID with a high responder rate. The occurrence of a pneumothorax is a frequent complication in the acute posttreatment phase $[1,17,18]$; however, no pneumothoraces occurred between the 6-month and 1-year visits. Seventy-eight percent of the initially treated patients retained the EBV over the 1-year study period, although $17 \%$ needed to undergo extra bronchoscopies with valve replacements to restore valve dysfunction.

Our 1-year follow-up results show that the largest improvements in $\mathrm{FEV}_{1}, \mathrm{RV}$, and SGRQ after EBV treatment are observed at 6 months after treatment, with a slight decline in these variables at the 1-year timepoint. However, the improvements for all endpoints, $\mathrm{FEV}_{1}, \mathrm{RV}$, and SGRQ, at 1 year remained statistically significant with clinically relevant improvements compared to baseline. The slight decline in lung function parameters, noted primarily in the homogeneous and lower lobe cohorts, did not result in a decline in exercise performance between 

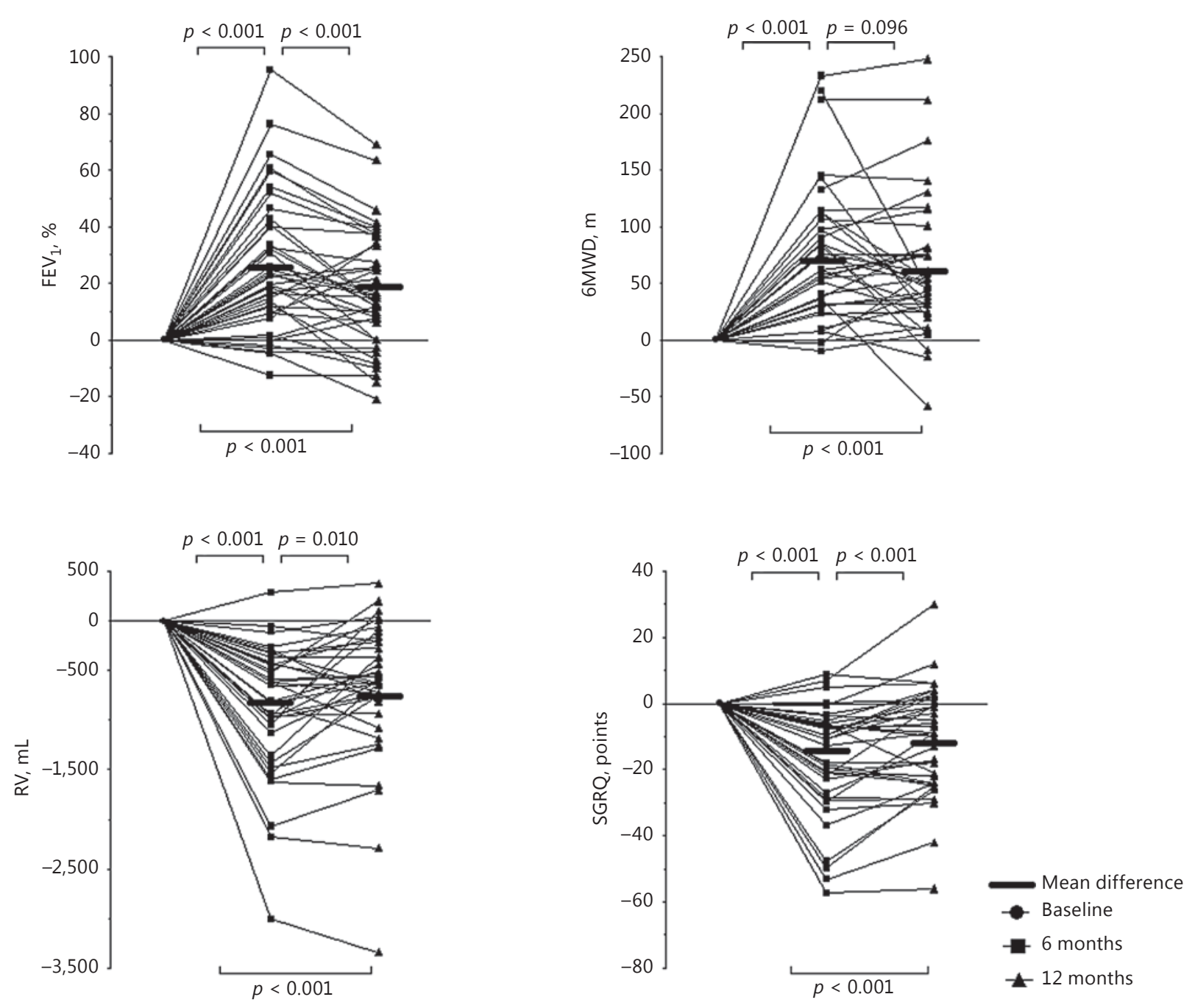

Fig. 3. Individual patient outcomes compared to baseline at 6 months and 1 year of follow-up of the patients who attended the voluntary 1-year follow-up visit $(n=40)$. The data are presented as change from baseline to 6 months and 1 year of follow-up. $\mathrm{FEV}_{1}$, forced expiratory volume in $1 \mathrm{~s} ; 6 \mathrm{MWD}, 6$-min walk distance, RV, residual volume; SGRQ, St. George's Respiratory Questionnaire.

the 6- and 12-month follow-up. Possible causes of the observed lung function loss are ongoing progression of emphysema, overexpansion of the nontreated ipsilateral lobe [4], and loss of EBV function. The durability of the treatment effect of improved lung function after the first year of successful treatment with EBV needs to be explored in larger studies with longer follow-up, which are currently underway (NCT01796392).

Importantly, also at 1 year, the benefit from EBV treatment was maintained not only in patients with a hetero- geneous emphysema distribution on high-resolution CT, but also in patients with homogeneous emphysema. Recently published data from a randomized clinical study in patients with homogeneous emphysema showed the benefits of EBV treatment at 3 months [3]. The present data provide important long-term (12 months) observations of persistent benefits in patients with homogeneous emphysema with limited treatment options including no surgical alternatives, with the NETT trial showing that surgical lung volume reduction in patients with a homo- 
Table 3. Serious adverse events at 1 year of follow-up in all treated patients $(n=64)$

\begin{tabular}{lcc}
\hline Event & $\begin{array}{c}0-6 \text { months } \\
\text { of follow-up }\end{array}$ & $\begin{array}{c}6 \text { months to } 1 \text { year } \\
\text { of follow-up }\end{array}$ \\
\hline Death (3\%) & 1 & 1 \\
COPD exacerbation (14\%) & 7 & 2 \\
Pneumonia (8\%) & 3 & 2 \\
$\quad$ Pneumonia treated lobe & 1 & 2 \\
Pneumonia nontreated & 2 & 0 \\
Pneumothorax (22\%) & 14 & 0 \\
Valve replacement (17\%) & 8 & 3 \\
Valve expectoration & 3 & 0 \\
Valve migration/dislocation & 3 & 3 \\
$\quad$ Increased complaints without benefit & 1 & 0 \\
Valve replacement with finally permanent valve removal (5\%) & 2 & 2 \\
Permanent valve removal (17\%) & 9 & 0 \\
Recurrent pneumothorax & 4 & 0 \\
Torsion of the bronchus & 2 & 0 \\
$\quad$ Pneumonia distal to valve & 1 & 2 \\
Granulation tissue and/or lack of efficacy & 2 & 0 \\
Stroke (3\%) & 2 & 0 \\
Paroxysmal atrial fibrillation (2\%) & 1 & 2 \\
\hline
\end{tabular}

Serious adverse events were all adverse events which were fatal, required or prolonged hospitalization, caused substantial risk of dying at the time of the event, resulted in permanent impairment of a body function, or required medical or surgical intervention to prevent permanent impairment of a body function. COPD, chronic obstructive pulmonary disease.

geneous emphysema is associated with higher mortality as compared to medical controls [19].

Pneumothorax was the most important serious adverse event in the first 6 months of the STELVIO trial, occurring predominantly during the immediate posttreatment period when patients were still hospitalized and under observation. In this 1-year follow-up study, no additional pneumothoraces were observed between 6 and 12 months. Despite this encouraging observation, future pneumothoraces may still occur, although it will be difficult to discriminate between treatment-related and spontaneous pneumothoraces. Another device-related event after 6 months of follow-up was permanent valve removal because of valve dislocation due to formation of granulation tissue, resulting in complaints like coughing and loss of valve efficacy. Formation of granulation tissue in response to implanted devices is a well-known and therapeutically challenging problem, also encountered after placement of central airway stents [20]. Removing the valves indeed resolves this granulation tissue formation; however, the beneficial lung volume reduction effects also disappear. Importantly, follow-up spirometry data from patients who were not able to retain their valves showed both $\mathrm{FEV}_{1}$ and FVC values comparable to baseline values at a median of 399 days after valve removal. One might consider surgical lung volume reduction in patients who demonstrate significant initial clinical benefit from the valve treatment, but were unfortunate to develop local airway granulation formation, leading to permanent valve removal [21].

Eight patients did not attend the 1-year follow-up visit, which could bias the outcome measures. Therefore, we collected the individual spirometry data from the patients' local hospitals. For these data, the conditions under which spirometry was performed were not know (pre- or postbronchodilator). The available data were predominantly assessed over more than 1 year after EBV treatment. The external spirometry data showed that only 1 patient had a decrease in both $\mathrm{FEV}_{1}$ and FVC compared to baseline. In 4 patients, both $\mathrm{FEV}_{1}$ and $\mathrm{FVC}$ and in 2 patients FVC were still improved compared to the baseline values, indicating that our results would not have been materially altered, even if they had visited our institution for their follow-up visit.

Our study demonstrated a statistically significant and clinically relevant improvement in the BODE index at the 
1-year follow-up. Two large randomized trials [22, 23] using the same EBV demonstrated comparable results 6 months after treatment, but only in patients with intact fissures and successful lobar occlusion [24]. Patients who underwent lung volume reduction surgery also demonstrated similar improvements in the BODE index after 6 months. This improvement in the BODE index was associated with a significant decrease in mortality [19]. Prolonged survival of subjects treated with EBV who achieved lobar atelectasis was also suggested in multiple cohorts [25-27]. While the data in our study has shown an improvement in the BODE index, suggesting a survival benefit, longer-term follow-up after EBV treatment is necessary to better investigate this potential survival benefit.

The uncontrolled study design after 6 months of follow-up in the present study is a limitation of our cohort study. We cannot correct for potential placebo effects; however, the efficacy outcomes in the original STELVIO trial were controlled with patients who did not receive EBV treatment, and these patients did not show any improvement after 6 months of follow-up.

A randomized controlled trial with a 1-year follow-up, ideally with a larger number of patients, would be useful to confirm our results. Another limitation is that not all patients who retained the valves were able to attend the voluntary 1-year follow-up visit, resulting in a smaller number of patients assessed at 1 year.

In summary, we present the 1-year follow-up results of patients with severe emphysema and absence of collateral ventilation who were previously treated with one-way EBV in the "STELVIO trial." We demonstrated clinically rele- vant and significant improvements in pulmonary function, exercise capacity, and quality of life, with good responder rates at 1 year after EBV treatment. An important observation is that no pneumothoraces occurred between 6 and 12 months of follow-up, in contrast to the $20 \%$ pneumothorax rate in the first weeks after treatment. Valve replacement or permanent valve removal can be required. We conclude that this 1-year follow-up study supports the use of EBV treatment in carefully selected patients with severe emphysema without collateral ventilation.

\section{Acknowledgements}

The authors would like to thank the pulmonary function technicians of the University Medical Center Groningen for their dedicated pulmonary function testing.

This initial study, the "STELVIO trial," was investigator initiated and supported by a grant (reg. No. 171101008 to University Medical Center Groningen) from the Netherlands (government) Organization for Health Research and Development ZonMw, The Hague, The Netherlands, and by an innovation fund by the University Medical Center Groningen, The Netherlands. All devices were commercially obtained from PulmonX, Redwood City, CA, USA (all catheters at regular market prices, and all valves at a 50\% reduced market list price).

\section{Author Contributions}

All authors contributed to the concept and design of the study, acquisition of the data or data analysis and interpretation, drafting of the article, revisions for important intellectual content, and final approval of the version to be published.

\section{References}

1 Klooster K, Ten Hacken NH, Hartman JE, Kerstjens HA, van Rikxoort EM, Slebos DJ: Endobronchial valves for emphysema without interlobar collateral ventilation. $\mathrm{N}$ Engl J Med 2015;373:2325-2335.

2 Valipour A, Slebos DJ, Herth F, Darwiche K, Wagner M, Ficker JH, Petermann C, Hubner RH, Stanzel F, Eberhardt R; IMPACT Study Team: Endobronchial valve therapy in patients with homogeneous emphysema: results from the IMPACT Study. Am J Respir Crit Care Med 2016;194:1073-1082.

3 Davey C, Zoumot Z, Jordan S, McNulty WH, Carr DH, Hind MD, Hansell DM, Rubens MB, Banya W, Polkey MI, Shah PL, Hopkinson NS: Bronchoscopic lung volume reduction with endobronchial valves for patients with heterogeneous emphysema and intact interlobar fissures (the BeLieVeR-HIFi study): a randomised controlled trial. Lancet 2015;386:1066-1073.

4 Brown MS, Kim HJ, Abtin FG, Strange C, Galperin-Aizenberg M, Pais R, Da Costa IG, Ordookhani A, Chong D, Ni C, McNitt-Gray MF, Tashkin DP, Goldin JG: Emphysema lung lobe volume reduction: effects on the ipsilateral and contralateral lobes. Eur Radiol 2012;22:1547-1555.

5 Miller MR, Crapo R, Hankinson J, Brusasco V, Burgos F, Casaburi R, Coates A, Enright $P$, van der Grinten $\mathrm{CP}$, Gustafsson P, Jensen R, Johnson DC, MacIntyre N, McKay R, Navajas D, Pedersen OF, Pellegrino R, Viegi G, Wanger J; ATS/ERS Task Force: General considerations for lung function testing. Eur Respir J 2005;26:153-161.
6 Miller MR, Hankinson J, Brusasco V, Burgos F, Casaburi R, Coates A, Crapo R, Enright P, van der Grinten CP, Gustafsson P, Jensen R, Johnson DC, MacIntyre N, McKay R, Navajas D, Pedersen OF, Pellegrino R, Viegi G, Wanger J; ATS/ERS Task Force: Standardisation of spirometry. Eur Respir J 2005;26:319338.

7 ATS Committee on Proficiency Standards for Clinical Pulmonary Function Laboratories: ATS statement: guidelines for the six-minute walk test. Am J Respir Crit Care Med 2002; 166:111-117.

8 Jones PW, Quirk FH, Baveystock CM, Littlejohns P: A self-complete measure of health status for chronic airflow limitation. The St. George's Respiratory Questionnaire. Am Rev Respir Dis 1992;145:1321-1327. 
9 Jones PW: COPD assessment test - rationale, development, validation and performance. COPD 2013;10:269-271.

10 Bestall JC, Paul EA, Garrod R, Garnham R, Jones PW, Wedzicha JA: Usefulness of the Medical Research Council (MRC) dyspnoea scale as a measure of disability in patients with chronic obstructive pulmonary disease. Tho$\operatorname{rax} 1999 ; 54: 581-586$.

11 Celli BR, Cote CG, Marin JM, Casanova C, Montes de Oca M, Mendez RA, Pinto Plata V, Cabral HJ: The body-mass index, airflow obstruction, dyspnea, and exercise capacity index in chronic obstructive pulmonary disease. N Engl J Med 2004;350:1005-1012.

12 Donohue JF: Minimal clinically important differences in COPD lung function. COPD 2005;2:111-124.

13 Hartman JE, Ten Hacken NH, Klooster K, Boezen HM, de Greef MH, Slebos DJ: The minimal important difference for residual volume in patients with severe emphysema. Eur Respir J 2012;40:1137-1141.

14 Puhan MA, Chandra D, Mosenifar Z, Ries A, Make B, Hansel NN, Wise RA, Sciurba F; National Emphysema Treatment Trial (NETT) Research Group: The minimal important difference of exercise tests in severe COPD. Eur Respir J 2011;37:784-790.

15 Jones PW: St. George's Respiratory Questionnaire: MCID. COPD 2005;2:75-79.

16 Welling JB, Hartman JE, Ten Hacken NH, Klooster K, Slebos DJ: The minimal important difference for the St George's Respiratory Questionnaire in patients with severe COPD. Eur Respir J 2015;46:1598-1604.
17 Valipour A, Slebos DJ, de Oliveira HG, Eberhardt R, Freitag L, Criner GJ, Herth FJ: Expert statement: pneumothorax associated with endoscopic valve therapy for emphysema - potential mechanisms, treatment algorithm, and case examples. Respiration 2014;87:513-521.

18 Gompelmann D, Herth FJ, Slebos DJ, Valipour A, Ernst A, Criner GJ, Eberhardt R: Pneumothorax following endobronchial valve therapy and its impact on clinical outcomes in severe emphysema. Respiration 2014;87:485-491.

19 Fishman A, Martinez F, Naunheim K, Piantadosi S, Wise R, Ries A, Weinmann G, Wood DE; National Emphysema Treatment Trial Research Group: A randomized trial comparing lung-volume-reduction surgery with medical therapy for severe emphysema. $\mathrm{N}$ Engl J Med 2003;348:2059-2073.

20 Gompelmann D, Eberhardt R, Schuhmann M, Heussel CP, Herth FJ: Self-expanding Y stents in the treatment of central airway stenosis: a retrospective analysis. Ther $\mathrm{Adv}$ Respir Dis 2013;7:255-263.

21 Beckers F, Lange N, Koryllos A, Picchioni F, Windisch W, Stoelben E: Unilateral lobe resection by video-assisted thoracoscopy leads to the most optimal functional improvement in severe emphysema. Thorac Cardiovasc Surg 2016;64:336-342.
22 Sciurba FC, Ernst A, Herth FJ, Strange C, Criner GJ, Marquette $\mathrm{CH}$, Kovitz KL, Chiacchierini RP, Goldin J, McLennan G; VENT Study Research Group: A randomized study of endobronchial valves for advanced emphysema. N Engl J Med 2010;363:1233-1244.

23 Herth FJ, Noppen M, Valipour A, Leroy S, Vergnon JM, Ficker JH, Egan JJ, Gasparini S, Agusti C, Holmes-Higgin D, Ernst A; International VENT Study Group: Efficacy predictors of lung volume reduction with Zephyr valves in a European cohort. Eur Respir J 2012;39:1334-1342.

24 Valipour A, Herth FJ, Burghuber OC, Criner G, Vergnon JM, Goldin J, Sciurba F, Ernst A; VENT Study Group: Target lobe volume reduction and COPD outcome measures after endobronchial valve therapy. Eur Respir J 2014;43:387-396.

25 Hopkinson NS, Kemp SV, Toma TP, Hansell DM, Geddes DM, Shah PL, Polkey MI: Atelectasis and survival after bronchoscopic lung volume reduction for COPD. Eur Respir J 2011;37:1346-1351.

26 Venuta F, Anile M, Diso D, Carillo C, De Giacomo T, D'Andrilli A, Fraioli F, Rendina EA, Coloni GF: Long-term follow-up after bronchoscopic lung volume reduction in patients with emphysema. Eur Respir J 2012;39:10841089.

27 Hopkinson NS, Toma TP, Hansell DM, Goldstraw P, Moxham J, Geddes DM, Polkey MI: Effect of bronchoscopic lung volume reduction on dynamic hyperinflation and exercise in emphysema. Am J Respir Crit Care Med 2005; 171:453-460. 